\title{
Pengembangan Aplikasi Inventaris Dan Peminjaman Peralatan Laboratorium Politeknik Gorontalo
}

\author{
Saprina Mamase ${ }^{1 *}$ \\ Sri Ariyanti Sabiku ${ }^{2 *}$ \\ Program Studi Teknik Informatika, Politeknik Gorontalo \\ email : saprinamamase@poligon.ac.id \\ email : Sriariyantisabiku@ poligon.ac.id
}

\begin{abstract}
Abstrak-Laboratorium di Politeknik Gorontalo digunakan untuk kegiatan pembelajaran maupun praktikum, secara umum alat dan bahan yang dimiliki disetiap laboratorium tersebut sudah lengkap dan memadai, masalah lain yang di temukan yakni peralatan yang sudah tidak diketahui keberadaanya, dapat menghambat mahasiswa dalam melakukan praktikum. Untuk itu penulis membuat sebuah "Aplikasi Inventari dan Peminjaman Peralatan Laboratorium Politeknik Gorontalo". Aplikasi ini di buat untuk mendukung kegiatan pengolahan dan kegiatan laboratorium di Politeknik Gorontalo. Diimplementasikan menggunakan bahasa pemrograman PHP dengan menggunakan framework Code Igniter serta menggunakan Database MySQL san software pendukung lainnya.
\end{abstract}

Kata Kunci : Inventaris, peminjaman, laboratorium, PHP, MySQL.

\section{PENDAhuluan}

Politeknik Gorontalo adalah Perguruan tinggi vokasional, Politeknik Gorontalo memiliki 3 Program Studi yaitu Teknik Informatika, Teknologi Hasil Pertanian, Mesin Peralatan Pertanian. Di setiap program studi memiliki masing-masing laboratorium. Laboratorium memiliki macam-macam peralatan dan bahan.

Saat ini sistem pengolahan data peralatan yang digunakan di laboratorium Politeknik Gorontalo masih dilakukan secara tertulis dengan cara mengisi form yang diberikan oleh petugas laboratorium sebagai bukti dan pegengan peminjaman. Dimana form tersebut akan di arsipkan ke inventarisasi peralatan, peminjaman peralatan, dan pengembalian peralatan, sehingga proses pengolahan dan keamanan data kurang terjamin serta proses penyediaan, pengecekan, dan pengolahan data memerlukan waktu yang cukup lama.

Laboratorium di Politeknik Gorontalo di gunakan untuk kegiatan pembelajaran maupun praktikum, secara umum peralatan dan bahan yang dimilki disetiap laboratorium tersebut sudah lengkap dan memadai, akan tetapi belum didukung dengan pengelolaan inventarisasi yang optimal. Sehingga menyebabkan pengelolaan yang kurang maksimal.

\author{
Nofayanti Saman ${ }^{1)}$ \\ Program Studi Teknik Informatika, Politeknik Gorontalo \\ email : nofayantisaman@gmail.com
}

Dengan adanya permasalahan tersebut penulis telah mengembangkan penelitian yang telah dilakukan oleh Astrit Kolanus sebelumnya. Pada penelitian Astrit Kolanus hanya melakukan penelitian tentang inventaris Laboratorium Teknik Informatika. Maka dari itu penulis melakukan pengembangan aplikasi untuk seluruh Laboratorium Politeknik Gorontalo dengan menambahkan peminjaman peralatan. Sehingga pengelolaan peralatan di setiap laboratorium yang ada di Politeknik Gorontalo bisa terintegrasi. Data yang ada akan digunakan dalam penelitian sebanyak 150 data peralatan laboratorium. Dengan adanya pengembangan sistem yang dibuat ini dapat mengatasi persoalan tersebut sehingga tidak menganggu proses praktikum di setiap laboratorium.

\section{METODE PENELITIAN}

\subsection{Analisa Sistem}

2.1.1 Sistem yang berjalan

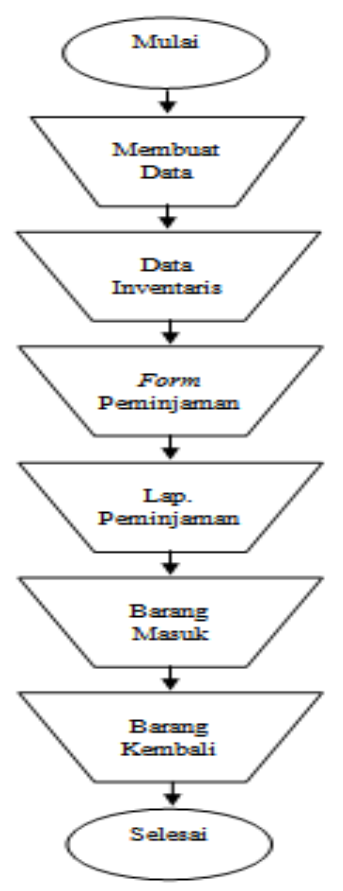

2.1.2 Bagan Alir Yang Usulan 


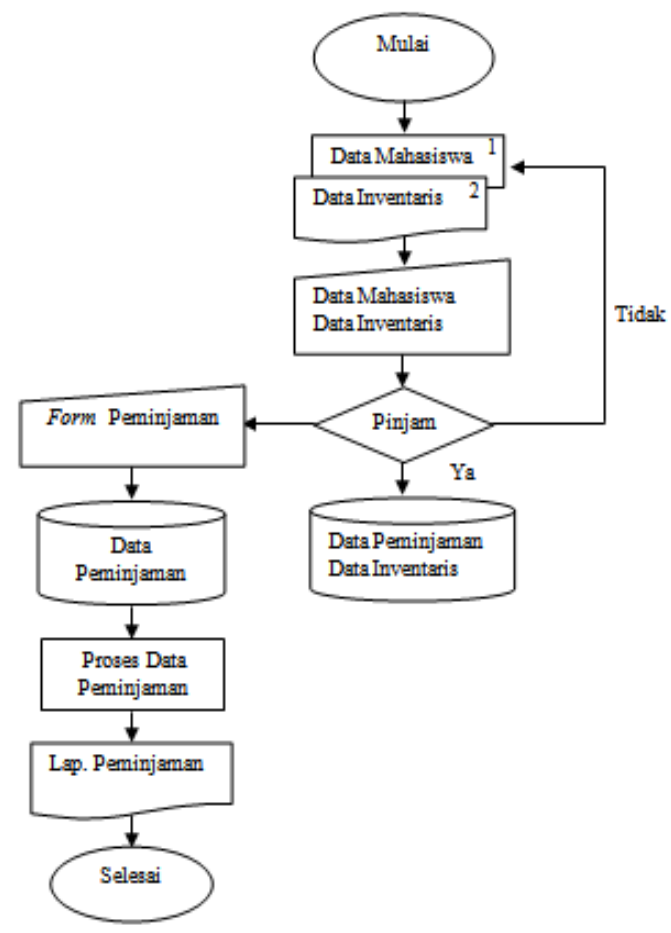

2.1.3 Bagan Alir Yang Usulan

\subsection{Diagram Konteks}

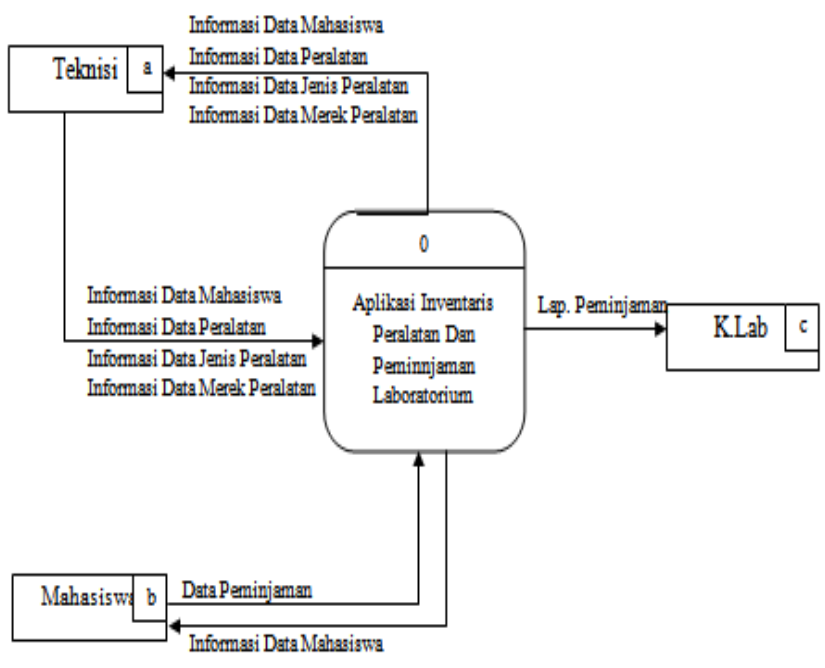

2.1.4 Bagan Alir Yang Usulan

\section{IMPLEMENTASI}

\subsection{Implementasi Aplikasi}

\subsubsection{Form Login Administrator}

Halaman ini merupakan tampilan untuk login administrator. Tampilan ini di lakukan untuk masuk ke form menu administrator seperti pada gambar 3.1

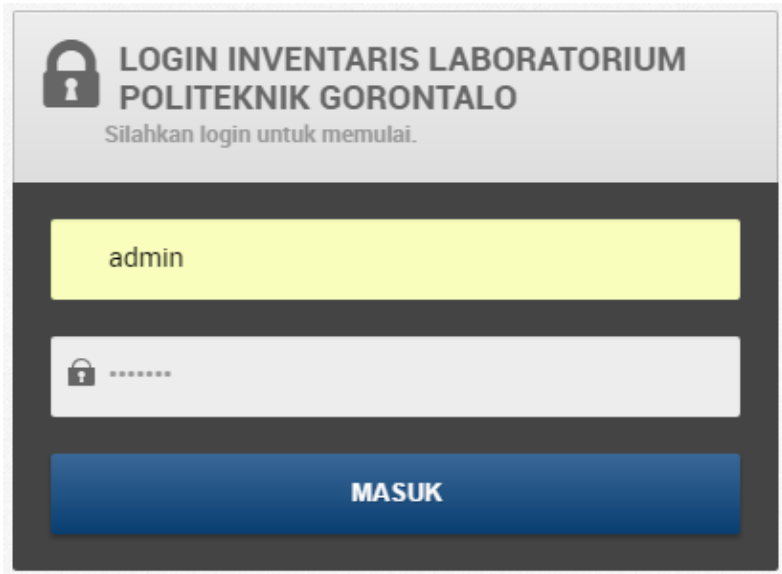

Gambar 3.2 Form Login Administrator

\subsubsection{Halaman Menu Administrator.}

Halaman ini untuk menampilkan menu administrator. Halaman ini meliputi Beranda dan Managemen User seperti pada gambar pada 3.2.

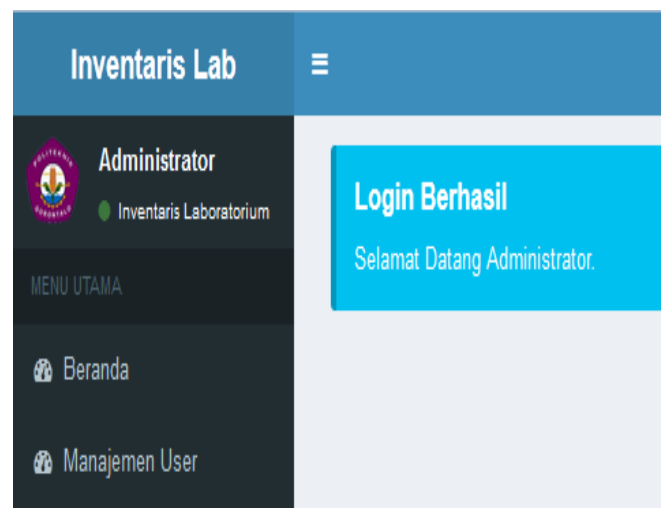

Gambar 3.2 Halaman Menu Administrator.

\subsection{Halaman Menu Master}

Halaman ini merupakan tampilan menu master. Halaman ini menampilkan semua yang ada di data master yaitu data mahasiswa, data peralatan, data jenis peralatan, data jenis merek seperti pada gambar 3.3

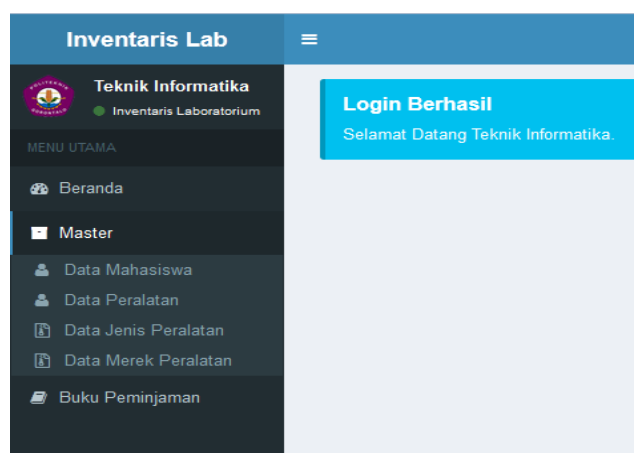

Gambar 3.3 Halaman Menu Master. 


\subsection{Form Data Peralatan}

Halaman ini di gunakan untuk menampilkan data peralatan yang ada di laboratorium seperti pada gambarb 3.2

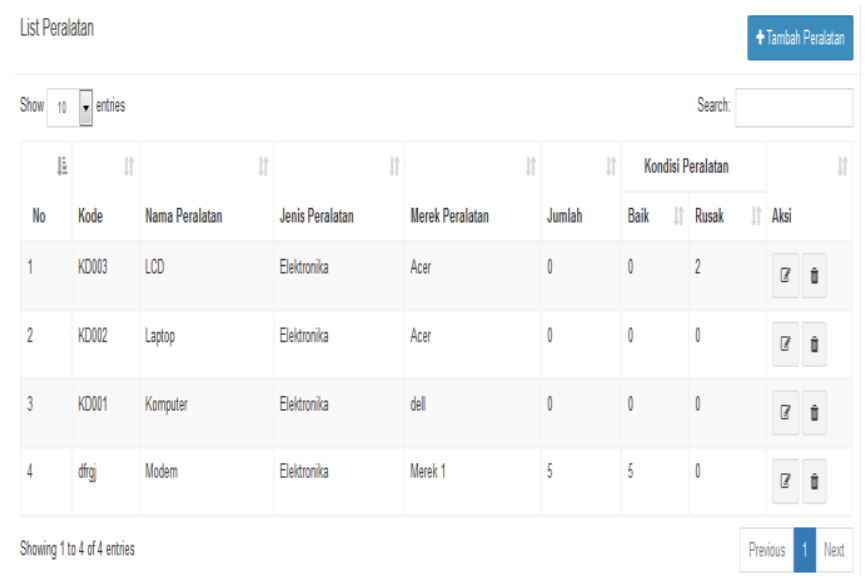

Gambar 3.4 Form Data Peralatan

\subsubsection{Form Data Mahasiswa}

Halaman ini di gunakan untuk menampilkan semua data mahasiswa. Halaman ini digunakan untuk memudahkan mahasiswa dalam proses peminjaman peralatan inventaris barang di laboratorium seperti pada gambar 3.5.

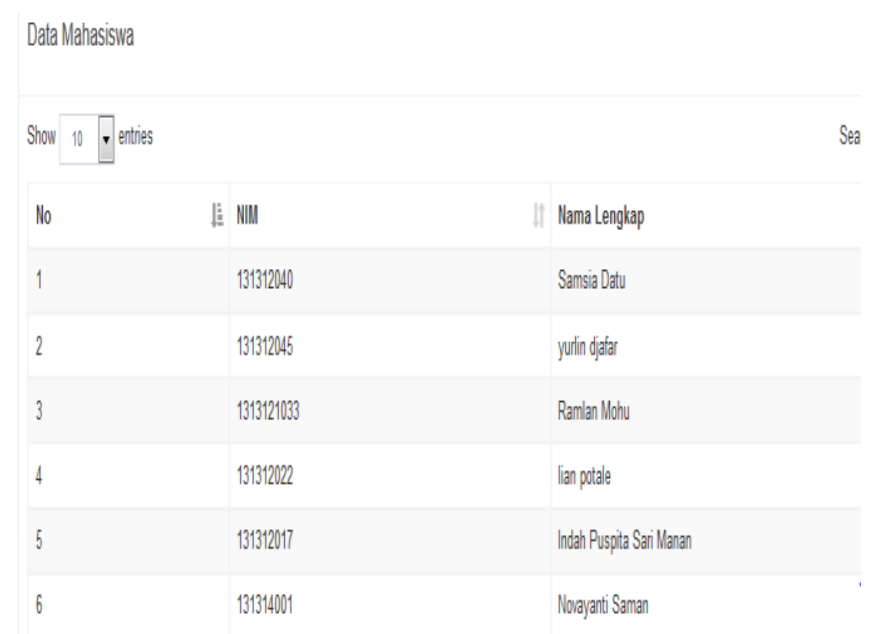

\section{Gambar 3.5 Form Data Mahasiswa}

\subsection{Halaman Buku Peminjaman}

Halaman ini digunakan untuk menampilkan buku peminjaman. Halaman ini menampilkan laporan daftar mahasiswa yang melakukan peminjaman seperti pada gambar 3.5
List Peminjaman

Show $10 \quad$ entries

$$
\begin{aligned}
& \text { No }{ }^{1} \text { NIM If Nama } \begin{array}{l}
\text { Nama If } \\
\text { Peralatan }
\end{array} \begin{array}{l}
\text { Tanggal } \\
\text { Peminjaman }
\end{array} \\
& 1 \quad 131312022 \text { lian LCD 2015-10-28 } \\
& \begin{array}{|l|l|l|l|} 
& \text { potale } \\
131312045 & \begin{array}{l}
\text { yurlin } \\
\text { djafar }
\end{array} & \text { Modem } 2015-10-28
\end{array} \\
& 131312045 \text { yurlin } \\
& \text { djafar Laptop } \\
& 131312040 \begin{array}{l}
\text { Samsia } \\
\text { Datu }
\end{array}
\end{aligned}
$$$$
\text { Showing } 1 \text { to } 4 \text { of } 4 \text { entries }
$$

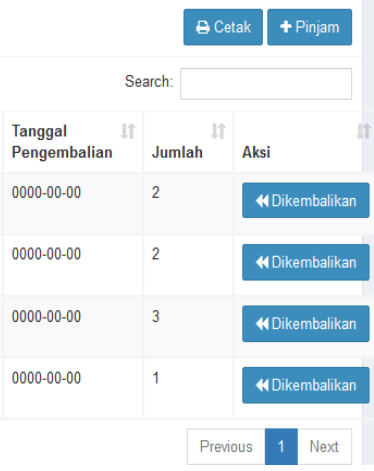

Gambar 3.6 Halaman Buku Peminjaman

\subsection{Form Peminjaman}

Halaman ini dilakukan untuk menampilkan peminjaman. Halaman ini digunakan melakukan peminjaman peralatan seperti pada gambar 3.7

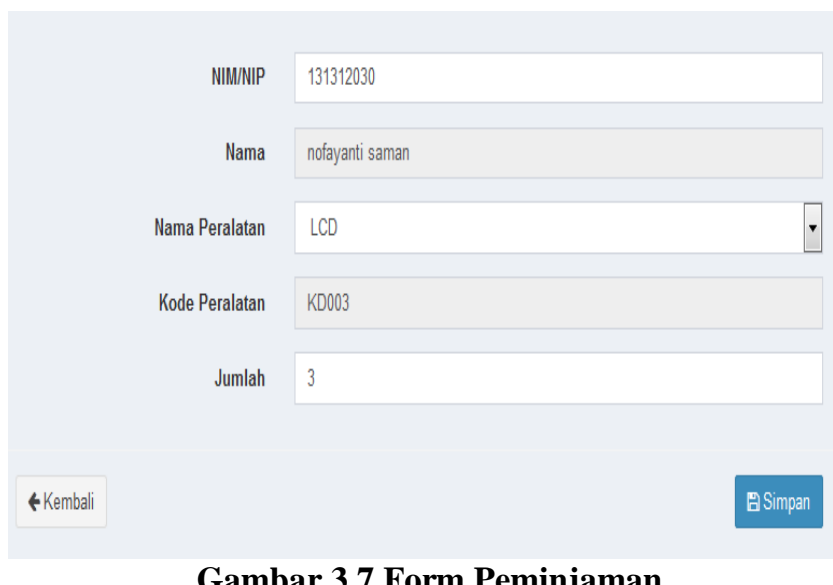

\subsubsection{Laporan}

Berikut ini hasil laporan cetak peminjaman peralatan laboratorium Politeknik Gorontalo seperti gambar 3.8

Laporan Peminjaman peralatan

LABORATORIUM POLTTEKNIK GORONTALO

PER TANGgal 10/01/2015 - 10/31/2015

\begin{tabular}{|l|c|l|l|l|l|l|}
\hline No & NIM & Nama & $\begin{array}{c}\text { Nama } \\
\text { Peralatan }\end{array}$ & $\begin{array}{c}\text { Tanggal } \\
\text { Peminjaman }\end{array}$ & $\begin{array}{c}\text { Tanggal } \\
\text { Pengembalian }\end{array}$ & \multicolumn{1}{|c|}{ Status } \\
\hline 1 & 131312040 & Samsia Datu & Laptop & $2015-10-14$ & $0000-00-00$ & $\begin{array}{l}\text { Eelum } \\
\text { Dikembalikan }\end{array}$ \\
\hline 2 & 131312022 & $\begin{array}{l}\text { Jamaludin } \\
\text { Nurkamiden }\end{array}$ & LCD & $2015-10-14$ & $0000-00-00$ & $\begin{array}{l}\text { Belum } \\
\text { Dikembalikan }\end{array}$ \\
\hline 3 & 131312024 & Misrin juma & Laptop & $2015-10-14$ & $0000-00-00$ & $\begin{array}{l}\text { Belum } \\
\text { Dikemballikan }\end{array}$ \\
\hline 4 & 131312022 & $\begin{array}{l}\text { lamaludin } \\
\text { Nurkamiden }\end{array}$ & Laptop & $2015-10-14$ & $0000-00-00$ & $\begin{array}{l}\text { Belum } \\
\text { Dikemballkan }\end{array}$ \\
\hline 5 & 131312030 & $\begin{array}{l}\text { nofayanti } \\
\text { saman }\end{array}$ & LCD & $2015-10-14$ & $2015-10-15$ & $\begin{array}{l}\text { Sudah } \\
\text { Dikemballikan }\end{array}$ \\
\hline 6 & 131314001 & $\begin{array}{l}\text { Novayanti } \\
\text { Saman }\end{array}$ & Laptop & $2015-10-12$ & $2015-10-13$ & $\begin{array}{l}\text { Sudah } \\
\text { Dikembalikan }\end{array}$ \\
\hline 7 & 131312017 & $\begin{array}{l}\text { Indah } \\
\text { Puspita Sari } \\
\text { Manan }\end{array}$ & Laptop & $2015-10-07$ & $2015-10-07$ & $\begin{array}{l}\text { Sudah } \\
\text { Dikembalikan }\end{array}$ \\
\hline 8 & 131312017 & $\begin{array}{l}\text { Indah } \\
\text { Puspita Sari }\end{array}$ & LCD & $2015-10-01$ & $2015-10-07$ & $\begin{array}{l}\text { Sudah } \\
\text { Dikembalikan }\end{array}$ \\
\hline
\end{tabular}

Gambar 3.6 Laporan Peminjaman. 


\section{PENUTUP}

\subsection{Kesimpulan}

Kesimpulan dari proyek akhir yang berjudul "Aplikasi Inventaris dan Peminjaman Peralatan di laboratorium Politeknik Gorontalo" adalah sebagai berikut :

1. Aplikasi ini dapat menginput data mahasiswa, data peralatan serta proses peminjaman.

2. Dapat mempermudah petugas laboratorium dalam mengakses data peminjaman peralatan.

3. Sistem ini memberikan laporan peminjaman peralatan berdararkan bulanan

\subsection{Saran}

Berdasarkan penelitian, ada beberapa saran untuk pengembangan aplikasi lebih lanjut, diantaranya sebagai berikut:

1. Aplikasi Inventaris dan peminjaman peralatan masih jauh dari kesempurnaan. Untuk itu penulis menyarankan pada penelitian selanjutnya dapat dikembangkan dengan menambahkan sms gateway.

2. Penyediaan sistem dengan Client-server.

\section{DAFTAR PUSTAKA}

[1] Anggraeni, Aprilianingtyas, (2013) Pengolahan laboratorium Biologi untuk menunjang kinerja Penggunaan Dan Pengelolaan Laboratorim Biologi SMA Negeri 2 Wonogiri. Universitas Negeri Semarang : Semarang.

[2] Bobihu, Yusran, (2013) Aplikasi Manajemen Laboratorium Komputer Teknik Informatika UIN Alauddin Makassar. UIN Alauddin Makassar : Makassar.

[3] Garniardi, Aris.M, dkk, (2009) Rancang Bangun Perangkat Lunak Sistem Informasi Laboratorium Fasilkmom Unsri. Universitas Sriwijaya : Sriwijaya

[4] Hidayatullah, Priyanto, (2014) Pemrograman Web. Bandung : Informatika Bandung.

[5] Kolanus, Astrit, (2013) Aplikasi inventaris asset laboratorium teknik informatika berbasis web di Politeknik Gorontalo. Gorontalo : Politeknik Gorontalo

[6] Ladjamudin, Bin Al-Bahra, (2013) Analisis dan Desain Sistem Informasi. Yogyakarta: Graha Ilmu. 


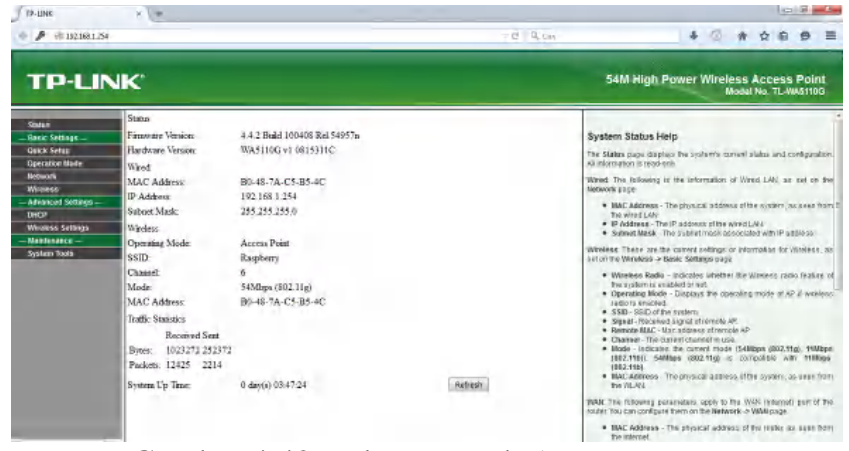

Gambar 4.42 Halaman Web Access point

Setelah masuk pada halaman web ada beberapa hal yang harus dikonfigurasi dimulai dari quick setup, setelah itu menekan tombol next sepertin yang ditunjukan pada gambar 4.43 :

Quick Setup
The quick setup will tell you how to configure the basic network parameters.
To continue, please click the Next button.
To exit, please click the Exit button.
Exit Next

\section{Gambar 4.43 Tampilan Quick Setup}

Setelah menekan tombol next maka masuk ke proses selanjunya yaitu choose acces point mode, ada 3 pilihan yang disediakan namun yang digunakan adalah mode AP (Acces Point) seperti yang ditunjukan pada gambar 4.44 :

\begin{tabular}{l} 
Quick Setup - Choose Operation Mode \\
\hline Please choose Operation Mode Type: \\
AP Client Router \\
AP Router \\
AP \\
Back Next
\end{tabular}

Gambar 4.44 Tampilan Choose Operation Mode

Setelah memilih AP pada acces point mode dan menekan next. Selanjutnya masuk pada quick setup wireless, pada wireless terdapat beberapa kolom yg terisi secara default. Kemudian diubah isi pada kolom seperti yang ditunjukan pada gambar 4.45 :

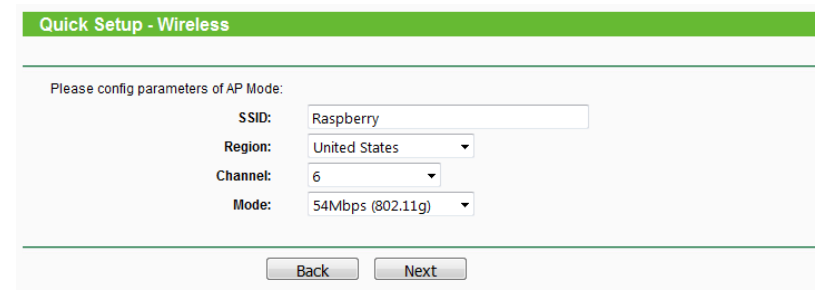

Gambar 4.45 Quick Setup Wireless

Kemudian untuk melanjutkan ke proses selanjuntya dengan menekan next, maka akan masuk ke proses quick setup finish seperti yang ditunjukan pada gambar 4.46 :

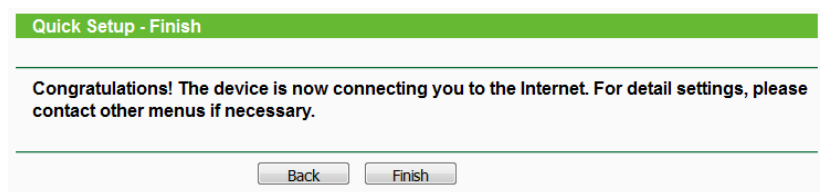

Gambar 4.46 Quick Setup Finish

Setelah menekan tombol finish, selanjutnya masuk pada konfigurasi DHCP. Konfigurasi DHCP ini bertujuan untuk mempermudah client untuk mengakses webcam server tanpa harus mengatur ip address lagi. Ada beberapa hal yang dikonfigurasi yaitu sebagai berikut :

1. DHCP server pilih enable untuk mengaktifkan DHCP server.

2. Start ip address end ip address untuk range ip dari 192.168.1.1 sampai 192.168.1.10

3. Default gateway 192.168.1.254 merupakan ip address dari access point.

4. Primary DNS 192.168.1.2 merupakan ip address dari raspberry atau ip webcam server.

Selanjutnya menekan save untuk menyimpan hasil konfigurasi, DHCP setting seperti yang ditunjukan pada gambar 4.47 :

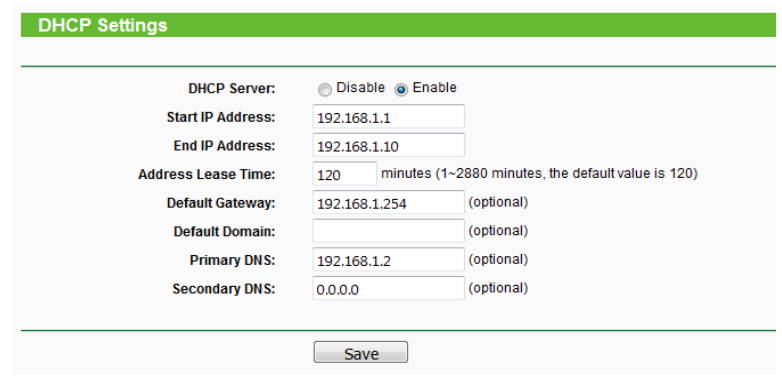

Gambar 4.47 Tampilan DHPC setting

Setelah menekan tombol maka sistem akan meminta restart seperti yang ditunjukan pada gambar 4.48:

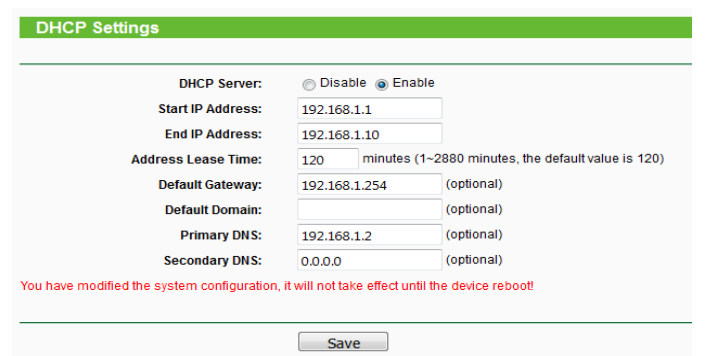

Gambar 4.48 DHCP Setting Meminta Untuk Reboot 


\subsection{Hasil dan Pengujian}

Pengujian medan robot ini dilakukan pada sebuah miniature sebuah ruangan dengan lebar $45 \mathrm{~cm}$ yang sulit dimasuki oleh manusia. Robot dapat berjalan dengan baik pada miniature ruangan ini. Untuk mengujikan informasi apa yang didapatkan robot sekaligus menguji webcam server saat berada dalam ruangan digunakan sebuah bola dan gelas berwarna. Seperti yang ditunjukkan pada gambar 4.53 dan 4.54 :

\section{DAFTAR PUSTAKA}

[1] Ali, M., 2009. Jurnal Universitas Negeri Yogyakarta : Pengembangan Media Pembelajaran Interaktif. Yogyakarta.

[2] Fathurrohman M., 2012. Jurnal. Penggunaan Multimedia dalam Pembelajaran. Halaman 6

[3] Lestari, D., 2012. Jurnal Arsip Teknik Informatika UMMI. Definisi Multimedia.

[4] Mulyana, E., 2012. App Inventor : Ciptakan Sendiri Aplikasi Androidmu. Penerbit Andi. Halaman 2

[5] Santosa, B., 2011. Repository UPI(Universitas Pendidikan Indonesia). Media Pembelajaran. Halaman 11-12

[6] Sofyan, A. F. dan Purwanto, A., 2008 Digital Multimedia : Animasi, Sound Editing, \& Video Editing. Yogyakarta : Andi Offset.Halaman 3-4

[7] Supriatna, D., 2009. Jurnal : Pengenalan Media Pembelajaran. Hal 3 dan 4

[8] Winarno, E. dan Zaki A., 2011. Hacking dan Programming dengan Android SDK untuk Advanced. Elex Media Komputindo.Halaman 5. 